\title{
Effects of Process Parameters on Friction Stir Weldability in Dissimilar Joints of AA5052 and Advanced High Strength Steel
}

\author{
Hee-Seon Bang*, Han-Sur Bang*, and Kyoung-Hak Kim*, \\ *Dept. of Welding and Joining Science Engineering, Chosun University, Gwangju, 61452, Korea \\ †Corresponding author: kimkh@chosun.kr \\ (Received October 5, 2020; Revised November 4, 2020; Accepted February 8, 2021)
}

\begin{abstract}
The dissimilar joining of aluminum (Al) alloy and steel has become attractive in the automotive sector to achieve lightweight components. However, joining Al to steel using conventional fusion welding processes is difficult because of their widely varying thermo-physical properties and the formation of intermetallic compounds (IMCs) at the Al-Fe joint interface. In the present study, the dissimilar joining of a $2.5 \mathrm{~mm}$ thick AA5052-H32 and a $1.4 \mathrm{~mm}$ thick DP590 steel sheet was performed using friction stir welding (FSW). Moreover, the effects of the process parameters on the mechanical properties and microstructure of FS welds was investigated. The tensile test results indicated that a higher heat input with increasing rotation speed and decreasing travel speed contributed to a higher tensile strength. The maximum tensile strength of the FS welds was $178 \mathrm{MPa}$, which exhibited a joint efficiency of approximately $79 \%$. As a result of scanning electron microscopy (SEM) with energy dispersive spectrometry (EDS) and X-ray diffraction (XRD) analysis, a thin interfacial layer of less than $1 \mu \mathrm{m}$ thickness comprising $\mathrm{Fe}_{4} \mathrm{Al}_{13} \mathrm{IMC}$ was observed at the dissimilar Al-Fe joint interface.
\end{abstract}

Key Words: Friction stir welding, Dissimilar Al/steel joints, Mechanical properties, Microstructure, Fracture behavior

\section{Introduction}

In recent years, lightweight in the automotive design and manufacture is one of the major key strategies to meet the growing demands for energy-saving, emissions reduction and improved fuel efficiency. Al alloys of 5XXX and 6XXX are the most promising light materials (LM) despite the relatively expensive cost of more than steel and they are extensively used to replace conventional steels in automotive components. $\mathrm{Al}$ alloys have high strength to weight ratio, good formability and corrosion resistance. In addition, the applications of advanced high strength steel (AHSS) that have the specific strength and good formability allow automotive design to effectively reduce the vehicle weight. Hence, in order to optimize the benefits provided by both materials of $\mathrm{Al}$ alloy and AHSS, the application of multi-material structures is increasingly being developed for automotive manufacturing technology.
The dissimilar welding of $\mathrm{Al}$ alloy to steel has been attracting considerable attentions to achieve the weight reduction for automotive applications. However, it is difficult to produce the sound joints due to vast differences in chemical and thermal properties (e.g. thermal conductivity, thermal expansion, heat capacity and melting point), lattice transformation and the mutual solid solubility (the nearly zero solid solubility of $\mathrm{Al}$ in $\mathrm{Fe}$ and the zero solid solubility of $\mathrm{Fe}$ in $\mathrm{Al})^{1}$. Especially, major issue associated with dissimilar joining is the formation of excessive IMCs, which forms at interface between $\mathrm{Al}$ alloy and steel due to both chemical reaction and inter-diffusion. According to the Fe-Al equilibrium phase diagram, IMCs of Fe-rich $\left(\mathrm{Fe}_{3} \mathrm{Al}, \mathrm{FeAl}\right)$ and Al-rich $\left(\mathrm{FeAl}_{2}, \mathrm{Fe}_{2} \mathrm{Al}_{5}\right.$ and $\left.\mathrm{FeAl}_{3}\right)$ can be formed at a range of chemical composition and temperature in Fe-Al system. In contrast to the Fe-rich IMCs, the Al-rich IMCs that are harder and more brittle are frequently found in dissimilar Al/steel joints. The Fe-rich IMCs are difficult to be formed because they have 
higher free energy than that of Al-rich IMCs. The mechanical properties of dissimilar $\mathrm{Al} /$ steel joints are significantly affected by thickness and chemical composition of IMCs. As the presence of thick IMCs at joint interface can result in crack nucleation, brittleness and low strength, it is necessary that the size and quantity of IMCs should be properly controlled with lower heat input during welding ${ }^{2-5)}$. Since the transient thermal cycle and short diffusion time during welding processes can form different types of IMCs, various processes such as cold metal transfer welding (CMT), advanced pulsed metal inert gas welding (Advanced Pulsed MIG), resistance spot welding (RSW), laser beam welding (LBM), ultrasonic spot welding (USW) and FSW have been attempted to join $\mathrm{Al}$ alloy to steel and enhance the joint performance $\mathrm{e}^{6-11)}$.

In solid state joining processes, FSW has become a promising solution for dissimilar joining of $\mathrm{Al}$ alloy to steel. This process with relatively small heat input is characterized to provide the extent of the formation of very limited IMCs. The diffusion of Fe and Al in solid phase is more difficult than liquid phase. In this regard, several researches on FSW of Al alloy to steel have been performed to examine a crucial influence of process parameters on mechanical performance of dissimilar FS welds depending on the formation and growth of IMC layer at the Al-Fe joint interface. Watanabe et.al investigated the effects of tool rotation speed, pin offset and pin diameter on tensile strength and microstructure in dissimilar FS welds of AA5083 alloy and SS400 mild steel sheet ${ }^{11)}$. They reported that the fracture with maximum tensile strength occurred along the interface between the steel fragment and the Al matrix when pin offset became positive at steel side. The IMC layer consisting of $\mathrm{FeAl}$ and $\mathrm{FeAl}_{3}$ were formed at the Al-Fe joint interface of upper region in FS welds, while no IMC was observed at central and bottom region of FS welds. In two researches of joining of $3 \mathrm{~mm}$ thick AA5052-H32 alloy to $3 \mathrm{~mm}$ thick high strength low alloy (HSLA) steel sheet by Ramachandran et al., the effect of tool axis offset and geometry of tool pin profile on the mechanical and metallographic characteristics of FS welds was investigated ${ }^{12,13)}$. The maximum joint strength of $188 \mathrm{MPa}$ indicating joint efficiency of about $91 \%$ was achieved using tool TC pin with $10^{\circ}$ taper angle at tool axis offset of $2 \mathrm{~mm}$ towards the $\mathrm{Al}$ side. The tensile strength of FS welds was significantly dependent upon the thickness of IMC layer formed at the Al-Fe joint interface. They reported that the typical softening at thermo-mechanically zone (TMAZ) close to nugget zone (NZ) occurred due to the reduction in dislocation density, and the steel fragments and IMC particles distributed in NZ as reinforcement were contributed to weld strength. Liu et al. joined $1.5 \mathrm{~mm}$ thick AA6061-T6 alloy to $1.4 \mathrm{~mm}$ thick transformation induced plasticity (TRIP) 780/800 steel sheet and quantitatively investigated the growth kinetics of IMC layer by relationships between IMC layer thickness and travel speed under process parameters on rotational speed and tool offset ${ }^{14)}$. They reported that travel speed was mainly related with the growth of interlayer thickness, whereas the variations in rotational speed and tool offset have an effect on the formation of IMC of FeAl and $\mathrm{FeAl}_{3}$ between chemical reaction and diffusion. The authors accomplished the highest ultimate tensile strength of $240 \mathrm{MPa}$ reaching joint efficiency of approximately $85 \%$ and a thin IMC layer with the thickness of less than $1 \mathrm{\mu m}$ at the Al-Fe joint interface. Movahedi et al. examined the effect of travel and rotation speed on the correlation between reaction layer formation and joint strength in dissimilar FS welds of AA5083 alloy to St-12 sheet $^{15)}$. The joint strength was significantly enhanced by decreasing the travel speed and increasing the rotation speed. Especially, the authors stated that a thin IMC layer with the thickness of less than $2 \mu \mathrm{m}$ has no effect on joint strength resulting in the fracture in base metal. Dehghani et al. reported the effect of travel speed, plunge depth, tilt angle and pin geometry on tensile strength and microstructure in dissimilar FS welds of $3 \mathrm{~mm}$ thick AA5186 alloy and $3 \mathrm{~mm}$ thick mild steel sheet ${ }^{16)}$. As a result, as a linear relationship between travel speed and IMC layer thickness, the increase in travel speed, which generated low heat input, exhibited the decrease IMC layer thickness. The maximum tensile strength of FS welds was found to be about 246 $\mathrm{MPa}$ at a thin IMC layer thickness of less than $0.5 \mu \mathrm{m}$. In all the above findings, it is reported that the process parameters including rotation speed, travel speed, pin offset distance, plunge depth and geometry of tool pin profile play an important role on mechanical performance, and the formation and growth of IMCs.

Tailor welded blanks (TWB), which is combining different thickness materials represents is one of the most interesting areas as the lightweight structures. The considerable potential for joining Al alloy of TWB with different thicknesses has been recently verified using $\mathrm{FSW}^{17)}$. However, the investigation of FSW on TWB of dissimilar materials with different thicknesses is not well investigated. Therefore, the aim of this study intends to assess the applicability of friction stir welded tailored blanks of dissimilar materials. Moreover, the comprehensive effect of process parameters on mechanical properties and microstructure characterization has been extensively investigated ${ }^{18)}$. 


\section{Materials used and Experimental method}

\subsection{Materials}

The base metals used in the present study were a 2.5 mm thick AA5052-H32 and a $1.4 \mathrm{~mm}$ thick SPFC DP590 steel sheet, whose dimensions were $200 \mathrm{~mm}(\mathrm{~L})$ $\times 100 \mathrm{~mm}(\mathrm{~B})$, respectively. The chemical compositions and mechanical properties of two base metals are listed in Table 1. The FSW tool material used for experiment was tungsten carbide (WC)-12\% Cobalt (Co). The tool shape of shoulder and pin was concave and frustum, respectively. The dimensions of FSW tool were as follow: the shoulder diameter is $18 \mathrm{~mm}$, the pin length is $1.4 \mathrm{~mm}$, the diameter of the top and bottom is $6 \mathrm{~mm}$ and $4 \mathrm{~mm}$, respectively.

\subsection{FSW process}

The schematic diagram of the experimental setup for FSW process is shown in Fig. 1. The AA5052-H32 and
SPFC590DP steel sheet were placed at retreating side (RS) and advancing side (AS), respectively. The hard material such as steel should be positioned at AS for successful joining configurations and pin offset located at Al alloy faying surface was further shifted toward steel ${ }^{11)}$. In the present study, in order to precisely control the pin offset, the charge-coupled device (CCD) camera was equipped with FSW system. The tilt angle of FSW tool was kept constant $3^{\circ}$ during all experiments. The process parameters used are listed in Table 2.

\subsection{Mechanical test}

Tensile test with tensile specimen perpendicular to welding direction according to ASTM E8 was performed using a universal testing machine (UTM) at a crosshead speed of $1 \mathrm{~mm} / \mathrm{min}$ at room temperature. The Vickers microhardness was measured along the transverse cross section of FS welds with a load of $500 \mathrm{~g}$ and dwell time of $10 \mathrm{~s}$. The erichsen cupping test based

Table 1 Chemical compositions and mechanical properties

\begin{tabular}{|c|c|c|c|c|c|c|}
\hline \multicolumn{7}{|c|}{ Chemical compositions (wt.\%) } \\
\hline Material & $\mathrm{C}$ & $\mathrm{Mn}$ & $\mathrm{Si}$ & $P$ & $S$ & $\mathrm{Fe}$ \\
\hline SPFC590DP & 0.0762 & 1.833 & 0.249 & 0.0108 & 0.0042 & Bal. \\
\hline \multirow{4}{*}{ AA5052-H32 } & $\mathrm{C}$ & $\mathrm{Mn}$ & $\mathrm{Si}$ & $\mathrm{P}$ & $\mathrm{S}$ & $\mathrm{Fe}$ \\
\hline & - & 0.01 & 0.09 & - & - & 0.21 \\
\hline & $\mathrm{Mg}$ & $\mathrm{Cu}$ & $\mathrm{Ti}$ & $\mathrm{Cr}$ & $\mathrm{Al}$ & \\
\hline & 2.34 & 0.01 & 0.011 & 0.19 & 97.14 & \\
\hline \multicolumn{7}{|c|}{ Mechanical properties } \\
\hline Material & \multicolumn{2}{|c|}{ Yield strength (MPa) } & \multicolumn{2}{|c|}{ Yield strength (MPa) } & \multicolumn{2}{|c|}{ Elongation (\%) } \\
\hline SPFC590DP & \multicolumn{2}{|c|}{459} & \multicolumn{2}{|c|}{623} & \multicolumn{2}{|c|}{24} \\
\hline AA5052-H32 & \multicolumn{2}{|c|}{188} & \multicolumn{2}{|c|}{220} & \multicolumn{2}{|c|}{12} \\
\hline
\end{tabular}

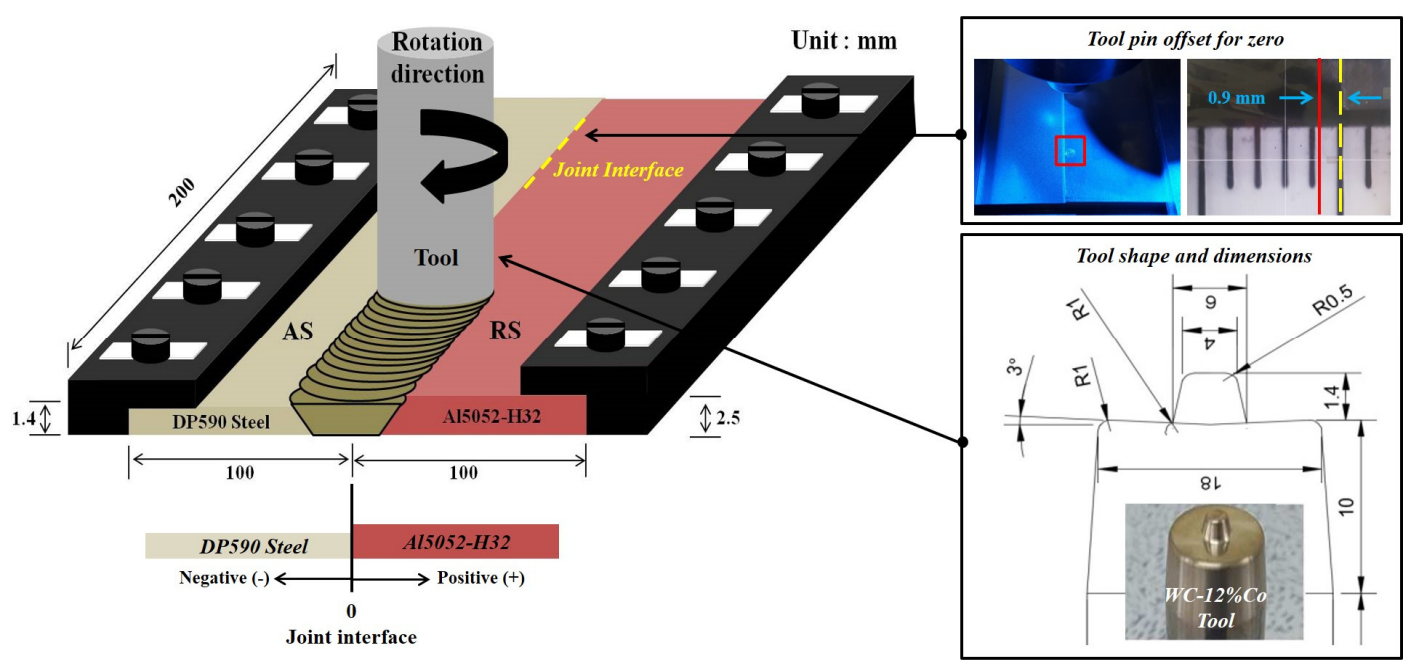

Fig. 1 Schematic illustration for FSW system adopting CCD camera 
Table 2 Friction stir welding parameters

\begin{tabular}{|c|c|}
\hline Process parameter & Value \\
\hline Rotation speed $(\mathrm{rpm})$ & $300,400,500$ \\
\hline Transverse speed $(\mathrm{mm})$ & $60,90,120$ \\
\hline Pin insert depth $(\mathrm{mm})$ & 0.8 \\
\hline Tool offset $(\mathrm{mm})$ & 0.9 \\
\hline Tool tilting angle $\left(^{\circ}\right)$ & 3 \\
\hline
\end{tabular}

on ASTM 643-09 was carried out to evaluate the formability of dissimilar FS welds using tip of the punch of $10 \mathrm{~mm}$ at test speed of $20 \mathrm{~mm} / \mathrm{min}$.

\subsection{Metallurgical test}

All samples for metallurgical observation were polished from SiC paper of 400 to 4000 grit and diamond suspension of 9,3 and 1 micron. After polishing, the metallographic samples were etched in $5 \%$ Nital reagent $(95 \mathrm{ml}$ ethanol $+5 \mathrm{ml}$ nitric acid) for $5 \mathrm{~s}$ and Tuckers reagent $\left(45 \mathrm{ml} \mathrm{HCI}+15 \mathrm{ml} \mathrm{HNO}_{3}+15 \mathrm{ml} \mathrm{HF}\right.$ $+25 \mathrm{ml}$ distilled water) for $10 \mathrm{~s}$ in sequence to observe the macrostructure and microstructure of FS welds using optical microscope. SEM equipped with EDS was utilized to quantify elements of IMC layer at the Al-Fe joint interface. In addition, the IMC phase was identified by an XRD using monochromatic CuKa radiation.

\section{Results and discussion}

\subsection{Bead profile and macrostructure}

The bead profile views of FS welds produced under different travel speed and rotation speed are shown in Fig. 2. When rotation speed increased from $300 \mathrm{rpm}$ to
Fig. 2 Bead profile view of FS welds with travel speeds and rotation speeds

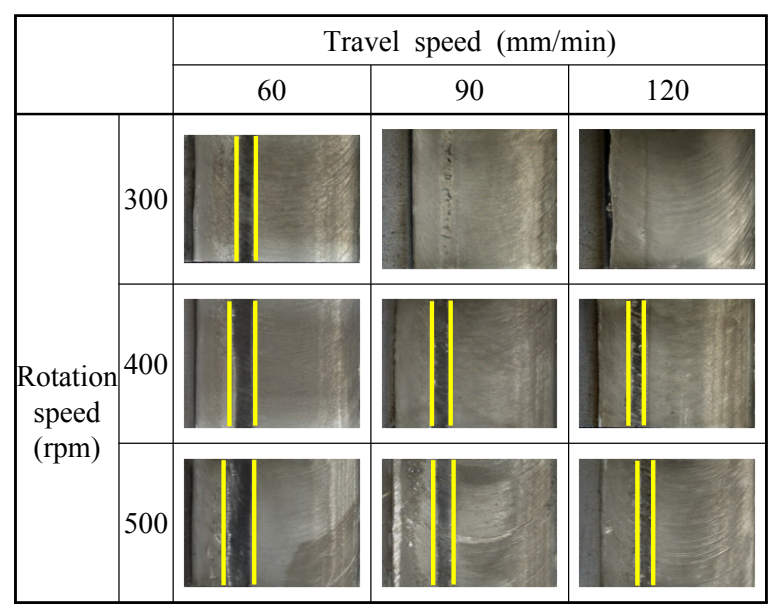

$500 \mathrm{rpm}$ at fixed travel speed of $60 \mathrm{~mm} / \mathrm{min}$, the deformed steel burr, which was formed on steel surface in the bead of FS welds exhibited a wider width caused by higher strain rate and higher welding temperature. The formation of steel burr was generated in initial plunging stage of pin inserted into dissimilar materials due to different thicknesses between Al alloy and steel. With the increase of travel speed ranging from $60 \mathrm{~mm} / \mathrm{min}$ to $120 \mathrm{~mm} / \mathrm{min}$, the total bead width significantly decreased as well as the width of deformed steel burr. Meanwhile, smooth bead morphology was observed at lower travel speed of $60 \mathrm{~mm} / \mathrm{min}$ in correspondence with weld pitch of $v / \omega$ that indicated a ratio of travel speed (v) to rotational speed $(\omega)$. This is due to the fact that energy generated per unit length of FS welds increases with decreasing weld pitch.

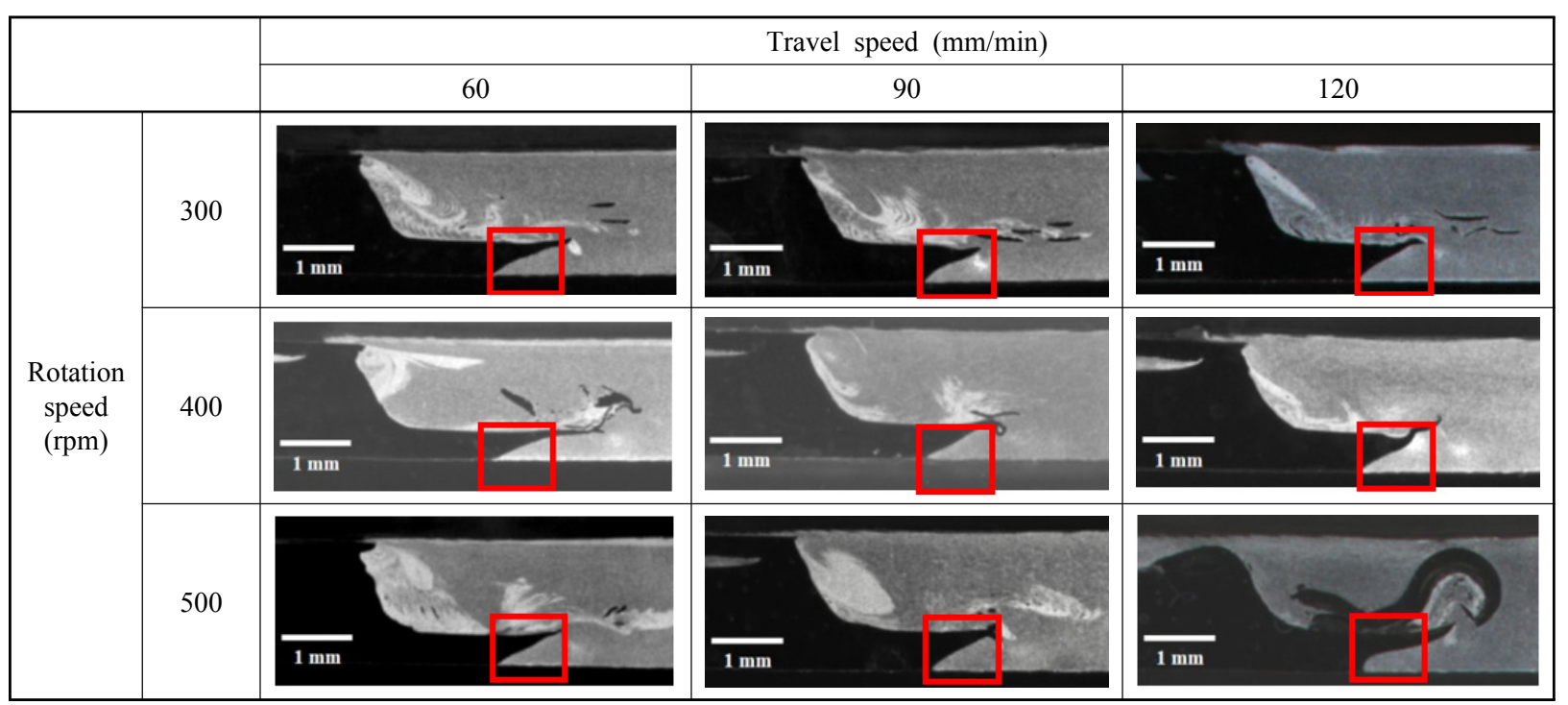

Fig. 3 Macrostructure view of FS welds with travel speeds and rotation speeds 
Fig. 3 shows the macrostructure views of FS welds. From the observation of macrostructure, no defects such as internal tunnel and crack were observed at joint interface. As seen in Fig. 3, the steel fragments with irregular shape and size in Al matrix were distributed by stirring action of pin. On the other hand, the reduction of effective thickness ranging from $1.81 \mathrm{~mm}$ to 1.99 $\mathrm{mm}$ occurred in all FS welds due to difference in thickness of two materials. This reason tends to be related to heat input, which is indicated as the ratio $(\omega / \mathrm{v})$ of rotation speed $(\omega)$ to travel speed $(v)$. In the present study, the ratio of $\omega / \mathrm{v}$ was from 2.5 to 8.33 in range of welding parameters on rotation speed and travel speed. It was revealed that effective thickness with a large amount of burr formed at al alloy side was decreased with the increase of heat input by lower travel speed at constant rotation speed. All FS welds have a weakness presenting the unwelded zone at bottom region of joint interface when the travel speeds are varied from 90 to $120 \mathrm{~mm} / \mathrm{min}$ at all rotation speeds. This result indicated that low heat input with increase in travel speed lead to the lack of plasticization caused by insufficient friction heat generation.

\subsection{Mechanical characteristics}

Fig. 4 shows the tensile strength of FS welds fabricated above-mentioned parameters; at travel speed of $60-120 \mathrm{~mm} / \mathrm{min}$ and at rotation speed of 300-500 rpm. The tensile test results exhibited that the tensile strength significantly decreased with the increase of travel speed ranging from $60 \mathrm{~mm} / \mathrm{min}$ to $120 \mathrm{~mm} / \mathrm{min}$ at different rotation speeds and increased with the increase of rotation speed at different travel speeds. The highest tensile strength of FS welds is $178 \mathrm{MPa}$, which is obtained under conditions of travel speed of $60 \mathrm{~mm} / \mathrm{min}$ and rotation speed of $500 \mathrm{rpm}$. Its joint efficiency reached approximately $79 \%$ of $\mathrm{Al}$ alloy base metal. After tensile test, the fractured surface of FS welds can be clearly divided into three featured types, which are as interface failure, NZ failure, and the mixed failure of interface + NZ, as shown in Fig. 5. The tensile strength which was fractured at joint interface is higher than that of tensile specimen fractured at NZ due to fragments of large size dispersed at RS. It can be inferred that under static tensile loading, the crack is propagating from interface of unwelded zone to large and small steel particles and then tensile specimen leads to final fracture. These results obtained from tensile test reveal that it is consistent with the result of macrostructure observation showing the presence of unwelded zone, as shown in Fig. 3 (unwelded zone is denoted by red outline). The unwelded zone of bottom region in dissimilar joints

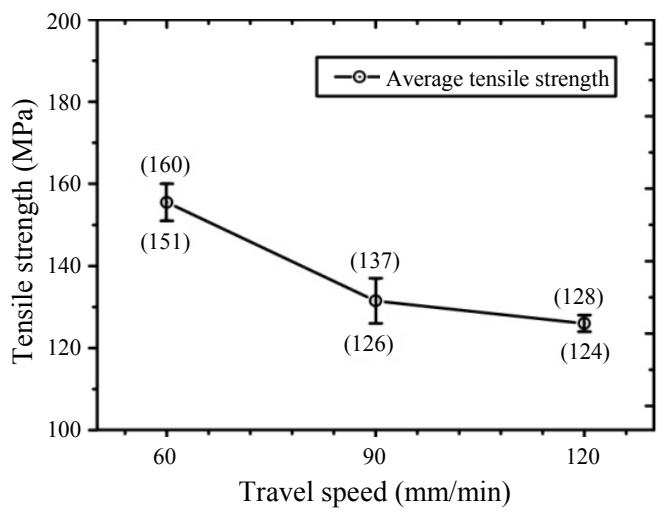

(a)

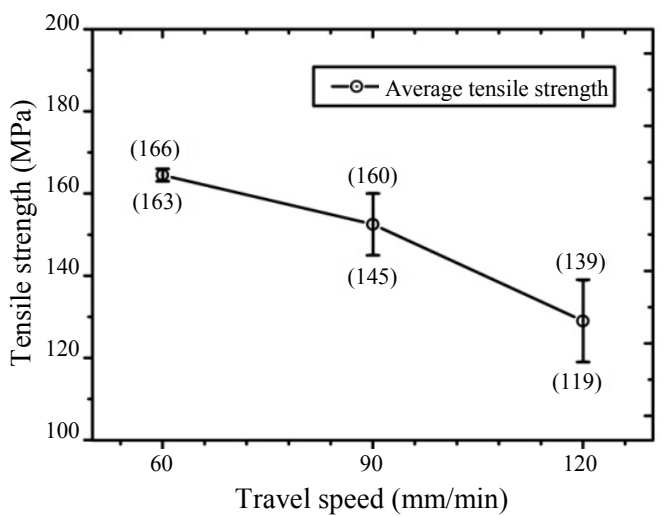

(b)

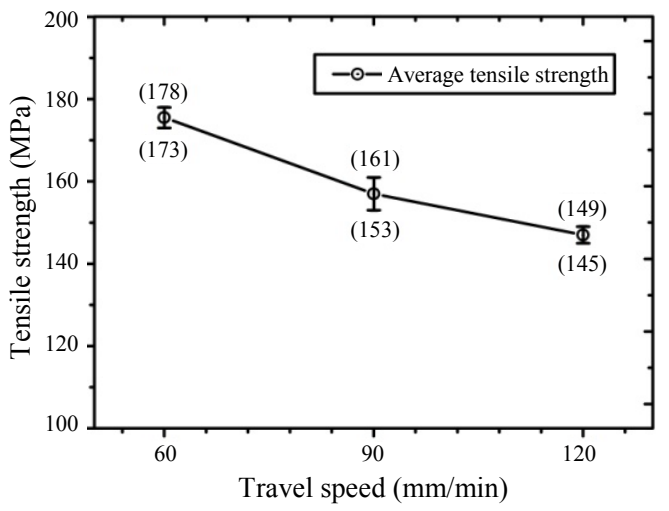

(c)

Fig. 4 Comparison of tensile strength of FS welds with different travel speeds at rotation speed; (a) 300 rpm, (b) $400 \mathrm{rpm}$ and (c) $500 \mathrm{rpm}$

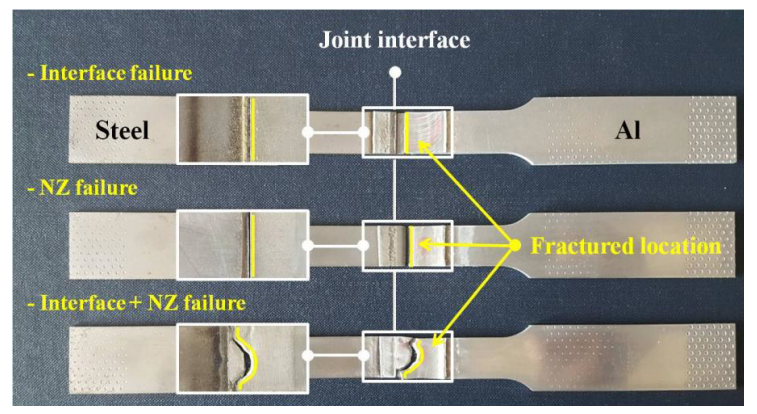

Fig. 5 Fractured tensile specimen of FS welds after tensile test 


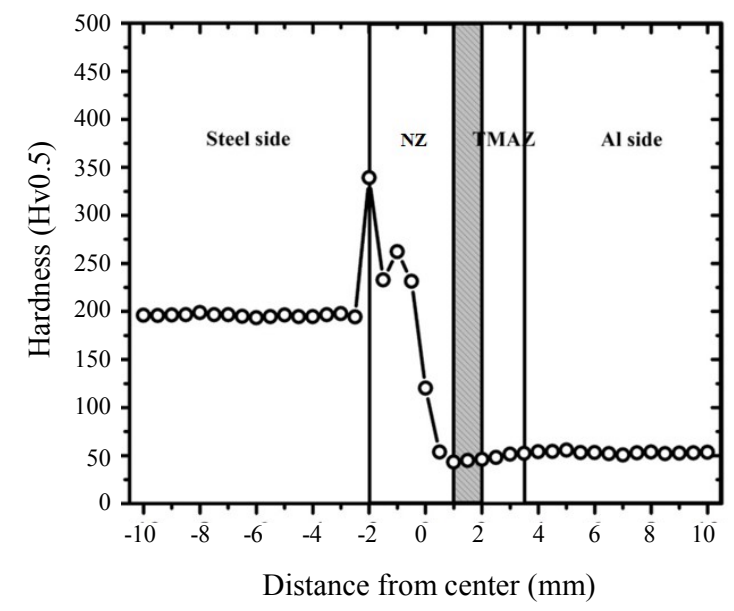

Fig. 6 Hardness distribution of FS welds

acts as path of crack propagation during tensile test. Consequently, it is necessary that the unwelded zone in dissimilar joints should be prevented by additional preheating source enabling enhanced material flow to enhance the sufficient plasticization ${ }^{19}$.

Fig. 6 shows the microhardness distribution measured along the middle line of transverse cross section of FS welds, which indicates the highest tensile strength after tensile test. The base metal hardness of Al5052-H32 and SPFC590DP steel used in the present study have ranges of 54-57 HV and 192-198 HV, respectively. The hardness values at the steel side adjacent to joint interface were significantly higher than that of steel base metal due to high hardenability and grain refinement. However, there was no distinct difference in hardness distribution in AS. The hardness values in TMAZ of $\mathrm{RS}$ close to $\mathrm{NZ}$ were slightly lower than that of the $\mathrm{Al}$ base metal. Similar to our result on this softening, Ramachandran et al. explained that localized decrement in hardness value is due to the softening caused by reduction in dislocation density, metallurgical recovery and annealing effect by thermal cycle during FSW (softening zone is denoted by gray outline) ${ }^{12)}$.

In order to evaluate the formability of FS welds, the erichsen cupping test was performed. Fig. 7 shows the fractured test samples on Al base metal and FS welds after erichsen cupping test. The test sample on FS welds was fractured under $10 \mathrm{kN}$ of the vertical sphere punch, which is approximately $49 \%$ lower than that of Al alloy sheet. The rupture occurred at the joint interface. This rupture seems to be more brittle at Al-Fe joint interface because it was drastically reduced the shift and load value of the vertical sphere punch due to formation of IMC and mismatch of mechanical properties on dissimilar materials.

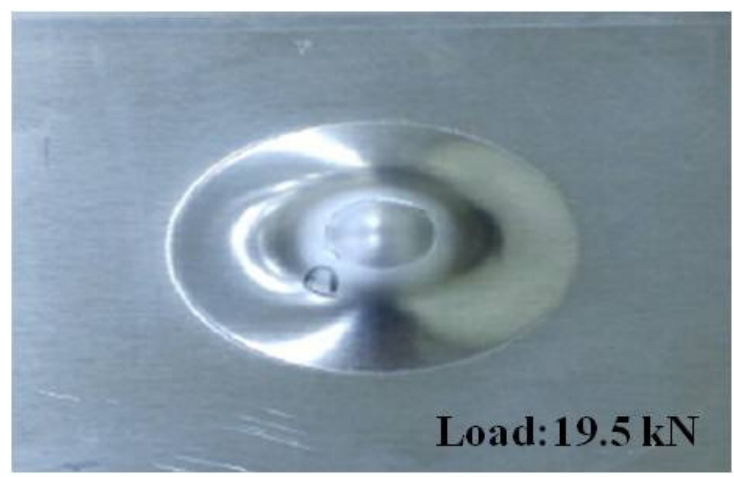

(a)

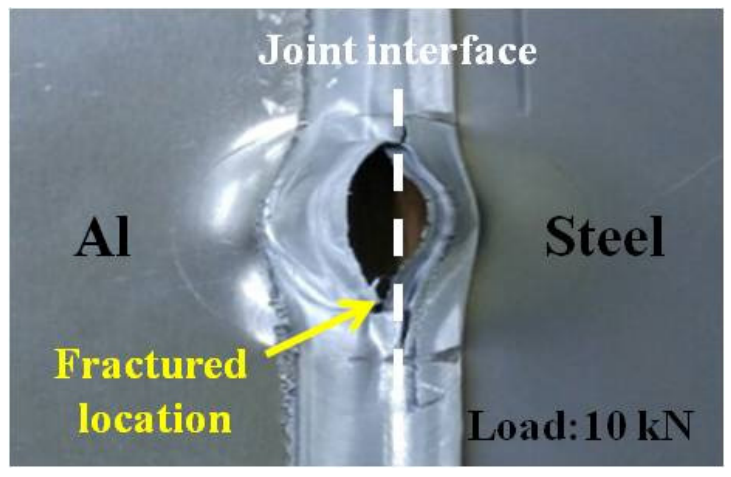

(b)

Fig. 7 Macrograph of (a) Al base metal and (b) FS welds after erichsen cupping test

\subsection{Metallurgical characteristics}

Fig. 8 shows the SEM micrographs of FS welds produced at travel speed of $60 \mathrm{~mm} / \mathrm{min}$ and at rotation speed of $500 \mathrm{rpm}$, where measured position was the central region of IMC layer. The results obtained from EDS point analysis of $\mathrm{Fe}$ and $\mathrm{Al}$ elements corresponding to the IMC layer and steel fragment scattered near Al-Fe joint interface are summarized in Table 3. As shown in Fig. 8 (a), the microstructure of FS welds exhibits visually internal micro defect-free, such as micro crack and void. The steel fragments with irregular shape and size consisting of 87.8 at.\% for Fe, 9.69 at.\% for $\mathrm{C}, 2.34$ at.\% for $\mathrm{Mn}$ and 0.17 at.\% for $\mathrm{P}$ were distributed near the IMC layer in Al matrix. It is seen from Fig. 8 (b) that a thin IMC layer with thickness of approximately $1 \mu \mathrm{m}$ was formed at joint interface and was also almost uniform. This interfacial layer had elemental compositions on 28.52 at.\% for $\mathrm{Fe}$ and 71.48 at. $\%$ for Al. According to the Fe-Al equilibrium phase diagram, this result of EDS point analysis for elemental composition indicates that two different IMCs could probably exist in stability range on $\mathrm{Fe}_{2} \mathrm{Al}_{5}$ and $\mathrm{Fe}_{4} \mathrm{Al}_{13}$. The XRD analysis was performed to clearly determine the IMC phase formed in the interfacial layer. Fig. 9 


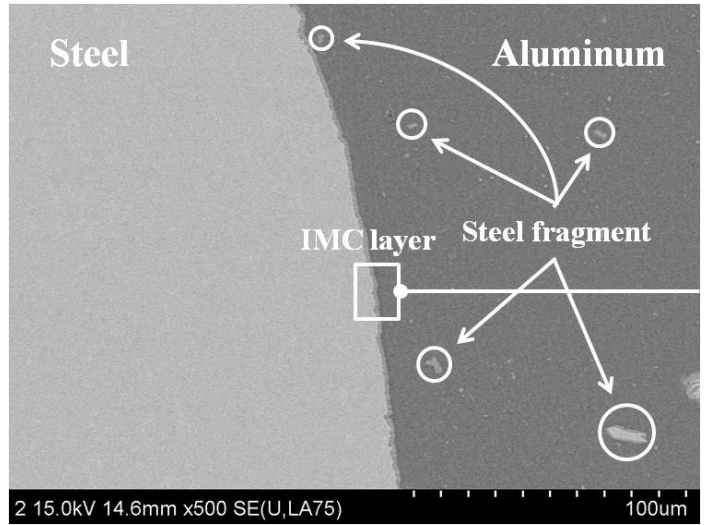

(a)

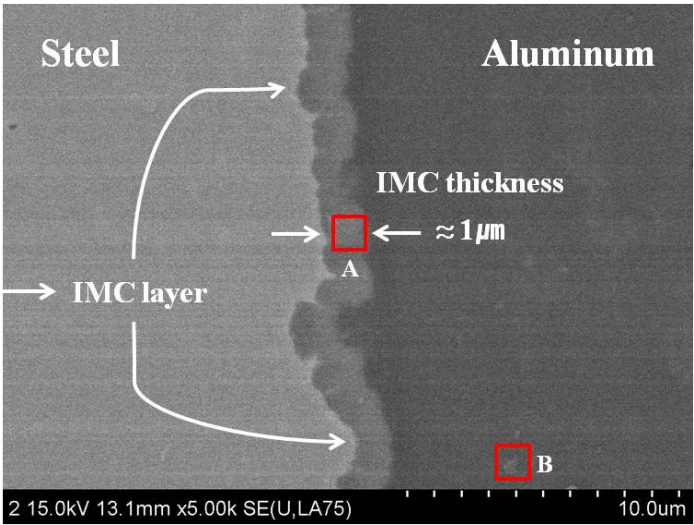

(b)

Fig. 8 SEM micrographs of joint interface (a) microstructure and (b) magnified view of rectangular region of (a)

Table 3 SEM-EDS results on composition analysis

\begin{tabular}{|c|c|c|c|c|c|}
\hline \multirow{2}{*}{ Area } & \multicolumn{5}{|c|}{ at.\% } \\
\cline { 2 - 6 } & $\mathrm{Fe}$ & $\mathrm{Al}$ & $\mathrm{C}$ & $\mathrm{Mn}$ & $\mathrm{P}$ \\
\hline Point (A) (Interfacial layer) & 28.52 & 71.48 & - & - & - \\
\hline Point (B) (Steel fragment) & 87.8 & - & 9.69 & 2.34 & 0.17 \\
\hline
\end{tabular}

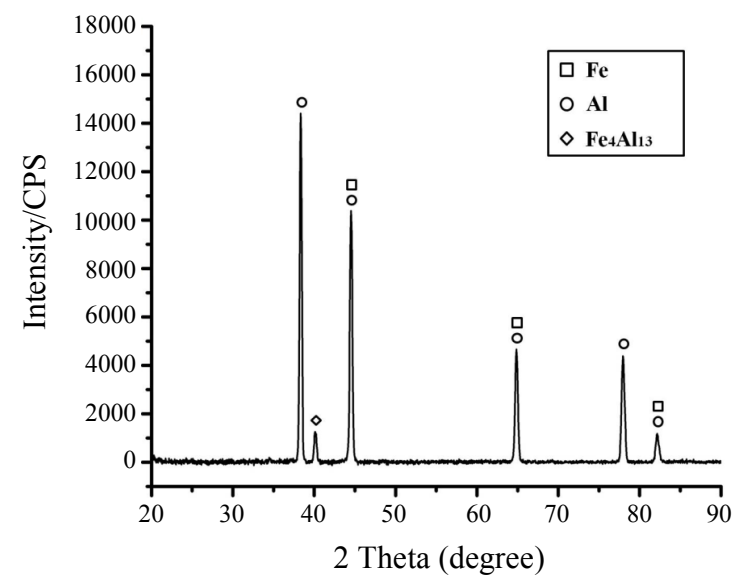

Fig. 9 XRD patterns of FS welds

shows the XRD spectrum of FS welds. As can be seen in Fig. 9, the $\mathrm{Fe}_{4} \mathrm{Al}_{13}$ IMC was detected at joint interface. This result is in a good agreement with the EDS analysis result. From reported literature studies, the Al-rich IMCs such as $\mathrm{Fe}_{4} \mathrm{Al}_{13}$ and $\mathrm{Fe}_{2} \mathrm{Al}_{5}$ are generally formed in the temperature range of $700{ }^{\circ} \mathrm{C}$ to 900 ${ }^{\circ} \mathrm{C}$, but the formation and growth of IMC could be limited at lower temperature. As the maximum temperature during FSW is lower than that of $\mathrm{Al}$ melting point, the interfacial reaction is solid-phase reaction between solid $\mathrm{Al}$ and solid Fe. Hence, at this stage, Al migrates towards the steel side, where it combines with $\mathrm{Fe}$ to form $\mathrm{Fe}_{4} \mathrm{Al}_{13}{ }^{20}$. On the other hand, the formation of IMC during FSW process was affected by mechanical cycle on local strain and stress generated from pin. Ramachandran et al. explained that an increase in pressure and higher strain rate can result in the formation of IMC layer at relatively lower temperature and thus the formation of $\mathrm{Fe}_{4} \mathrm{Al}_{13}$ IMC is to be likely under FSW temperature, pressure and strain rate ${ }^{13)}$.

\section{Conclusion}

In the present study, dissimilar joining of different thicknesses with a $2.5 \mathrm{~mm}$ thick AA5052-H32 and a $1.4 \mathrm{~mm}$ thick DP590 steel sheet has been investigated using FSW. The crucial effect of process parameters on mechanical properties and microstructure of FS welds was examined. The results can be summarized as follow:

1) The highest tensile strength of FS welds produced under conditions of travel speed of $60 \mathrm{~mm} / \mathrm{min}$ and rotation speed of $500 \mathrm{rpm}$ is $178 \mathrm{MPa}$, which is a joint efficiency of about $79 \%$ of $\mathrm{Al}$ alloy. For effect of process parameters on tensile strength, the tensile strength increases with increasing rotation speed and decreasing travel speed.

2) The localized decrement in hardness value in TMAZ of RS close to NZ was observed due to the typical softening caused by reduction in dislocation density, metallurgical recovery and annealing effect during FSW thermal cycle.

3) From results of EDS and XRD analysis, $\mathrm{Fe}_{4} \mathrm{~A}_{13}$ IMC with interfacial layer thickness of less than $1 \mu \mathrm{m}$ was detected at Al-Fe joint interface. This may be inferred that tensile strength is significantly dependent upon the thickness of interfacial layer formed at interface. Therefore, controlling the interfacial layer thickness can be more important in dissimilar joining. 


\section{Acknowledgement}

This study was supported by research funds from Chosun University, 2019.

ORCID: Hee-Seon Bang: https://orcid.org/0000-0003-0579-4738 ORCID: Han-Sur Bang: https://orcid.org/0000-0002-0753-3745 ORCID: Kyoung-Hak Kim: https://orcid.org/0000-0002-4889-2824

\section{References}

1. M. M. Atabaki, M. Nikodinovski, P. Chenier, J. Ma, M. Harooni, and R. Kovacevic, Welding of aluminum alloy to steels: an overview, J. Manuf. Sci. Prod. 14 (2014) 59-78.

https://doi.org/10.1515/jmsp-2014-0007

2. W. Zhang, D. Sun, L. Han, W. Gao, and X. Qiu, Characterization of intermetallic compounds in dissimilar material resistance spot welded joint of high strength steel and aluminum alloy, INIJ int. 178 (2011) 342-349. https://doi.org/10.2355/isijinternational.51.1870

3. L. Xu, L. Wang, Y. C. Chen, J. D. Robson, and P. B. Prangnell, Effect of interfacial reaction on the mechanical performance of steel to aluminum dissimilar ultrasonic spot welds, Metall. Mater. Trans. A-Phys. Metall. Mater. Sci. 47A (2016) 334-346. https://doi.org/10.1007/s11661-015-3179-7

4. H. C. Chen, A. J. Pinkerton, L. Li, Z. Liu, and A. T. Mistry, Gap-free fibre laser welding of Zn-coated steel on Al alloy for light-weight automotive applications, Mater. Des. 32 (2011) 495-504.

https://doi.org/10.1016/j.matdes.2010.08.034

5. H. Springer, A. Kostka, E. J. Payton, D. Raabe, A. Kaysser-Pyzalla, and G. Eggeler, On the formation and growth of intermetallic phase during interdiffusion between low-carbon steel and aluminum alloys, Acta Mater. 59 (4) (2011) 1586-1600. https://doi.org/10.1016/j.actamat.2010.11.023

6. L. Agudo, D. Eyidi, C. H. Schmaranzer, E. Arenholz, N. Jank, J. Bruckner, and A. Pyzalla, Intermetallic FexAly-phase in a steel/Al-alloy fusion weld, $J$. Mater. Sci. Technol. 42 (2007) 4205-4214.

7. A. Das, M. Shome, S. F. Goecke, and A. De, Joining of aluminium alloy and galvanized steel using a controlled gas metal arc process, J. Manuf. Process. 27 (2017) 179-187. https://doi.org/10.1016/j.jmapro.2017.04.006

8. N. Chen, H. P. Wang, B. E. Carlson, D. R. Sigler, and M. Wang, Fracture mechanisms of $\mathrm{Al} /$ steel resistance spot welds in coach peel and cross tension testing, J. Mater. Process. Technol. 252 (2018) 348-361. https://doi.org/10.1016/j.jmatprotec.2017.09.035
9. M. J. Rathod and M. Kutsuna, Joining of aluminum alloy 5052 and low-carbon steel by laser roll welding, Weld. J. 83 (2004) 16-26.

10. T. Watanabe, H. Sakuyama, and A. Yanagisawa, Ultrasonic welding between mild steel sheet and Al-Mg alloy sheet, J. Mater. Process. Technol. 209 (2009) 5475-5480. https://doi.org/10.1016/j.jmatprotec.2009.05.006

11. T. Watanabe, H. Takayama, and A. Yanagisawa, Joining of aluminum alloy to steel by friction stir welding, J. Mater. Process. Technol. 178 (2006) 342-349. https://doi.org/10.1016/j.jmatprotec.2006.04.117

12. K. K. Ramachandran, N. Murugan, and S. Shashi Kumar, Friction stir welding of aluminum alloy AA5052 and HSLA steel, Weld. J. 94 (2015) 291-300.

13. K. K. Ramachandran, N. Murugan, and S. Shashi Kumar, Effect of tool axis offset and geometry of tool pin profile on the characteristics of friction stir welded dissimilar joints of aluminum alloy AA5052 and HSLA steel, Mater. Sci. Eng. A-struct Mater. Prop. Microstruct. Process. 639 (2015) 219-233. https://doi.org/10.1016/j.msea.2015.04.089

14. X. Liu, S. Lan, and J. Ni, Analysis of process parameters effects on friction stir welding of dissimilar aluminum alloy to advanced high strength steel, Mater. Des. 59 (2014) 50-62.

https://doi.org/10.1016/j.matdes.2014.02.003

15. M. Movahedi, A. H. Kokabi, S. M. Seyed Reihani, and H. Najafi, Effect of tool travel and rotation speeds on weld zone defects and joint strength of aluminium steel lap joints made by friction stir welding, Sci. Technol. Weld. Join. 17 (2012) 162-167. https://doi.org/10.1179/1362171811Y.0000000092

16. M. Dehghani, A. Amadeh, and S. A. A. Akbari Mousavi, Investigations on the effects of friction stir welding parameters on intermetallic and defect formation in joining aluminum alloy to mild steel, Mater. Des. 49 (2013) 433-441. https://doi.org/10.1016/j.matdes.2013.01.013

17. C. S. Ro, H. S. Bang, H. S. Bang, S. J. Yoo, J. H. Kim, and E. G. Choi, Influence of workpiece tilting angle on joint properties in tailor friction stir welded blanks of aluminium alloy 5052-H32, J. Weld. Join. 36 (5) (2018) 39-44. https://doi.org/10.5781.JWJ.2018.36.5.5

18. K. H. Kim, Ph. D. thesis, The weldability of aluminium alloy and advanced high strength steel with different thicknesses by hybrid friction stir welding, Chosun University, Gwangju (2019).

19. H. S. Bang, H. S. Bang, H. S. Kim, J. H. Kim, I. H. Oh, and C. S. Ro, A study on the weldability and 
mechanical characteristics of dissimilar materials butt joints by laser assisted friction stir welding, $J$. Weld. Join. 28 (6) (2010) 70-75.

https://doi.org/10.5781.KWJS.2010.28.6.070
20. M. W. Safeen and P. R. Spena, Main issues in quality of friction stir welding joints of aluminum alloy and steel sheets, Met. 9 (5) (2019) 1-22.

https://doi.org/10.3390/met9050610 